\title{
The crustal density structures and deformation scratches in the Qinghai-Tibet Plateau
}

\author{
Yanyun $\mathrm{Sun}^{1}$, Wencai Yang ${ }^{2,3} *$, Zunze $\mathrm{Hou}^{2}$, Changqing $\mathrm{Yu}^{3}$
}

1China Aero Geophysical Survey \& Remote Sensing Center for Land and Resources, Beijing 100083, China

2 School of Geophysics and Information Technology, China University of Geosciences, Beijing 100083, China

3 Institute of Geology, China Academy of Geological Sciences, Beijing 100037,China

*communication author, E-mail: yangwencai@cashq.ac.cn,yysun2009@126.com 


\begin{abstract}
After introducing the principals of the multi-scale scratch analysis method of regional gravity data, this paper presents the results of its application to the Qinghai-Tibet Plateau, producing three sets of density disturbance, ridge coefficient, and edge coefficient images. The density disturbance images can be used to delineate the hardness and rheological properties of continental tectonic units. The ridge coefficient images can be used to delineate deformation belts, and the edge coefficient images can be used to determine positioning boundaries of the structural division of the units. These images provide crustal geological and tectonic information from different aspects with depth information, which are able to give quantitative constrains to any possible tectonic models. To the upper crust, these results are basically coincident with surface geological and tectonic mapping. They can also provide more structural information of the middle and lower crust, which conventionally is hard to be accurately inferred. For instance, the density disturbance images show the source-zones and squeezed flows of channel flows in the lower crust, as well as the position of the subduction front of the Indian plate beneath the Himalayan mountain range. The ridge coefficient images provide the positions of suture zones, deformation and subduction volcanic belts, ancient collision belts and strike-slip zones. By combining with these edge coefficient images, one can draw out tectonic maps with different structural units in the middle and lower crust. For example, very high density terranes such as the Kashmir and Chayuhe, are divided from the Himalayan terrane, giving physical reasons for the formation of the western and eastern structural knots in the India-Eurasia collisional belt. The multi-scale scratch analysis not only provides the plane geometry of structures and deformation belts, but also their depth extension and stereoscopic patterns. For instance, a decrease of the low-density volume from the lower crust to the upper implies possible diapiric intrusions of the low-density channel flows.
\end{abstract}

Key words: Qinghai-Tibet Plateau, multi-scale scratch analysis, density disturbance, deformation belts, subduction front, channel flow, structural knots 


\section{Introduction}

Previous research of the lithospheric structures and continental dynamics in the QinghaiTibet Plateau, a remarkable geological region in the world, have already presented tremendous significant data (Molnar and Paul, 1975; Molnar, 1988; Harrison et al., 1992; Avouac and Tapponnier, 1993; Jolivet and Hataf, 2001; Xu et al., 2009). However, current geological data is predominantly obtained from surface observations, with many of the geophysical data collected only from certain regional profiles. These data might not be sufficient for constructing three-dimensional images of crustal structure. Although seismic tomography can acquire three-dimensional images of seismic wave velocity perturbations, its spatial resolution is hardly sufficient for fine crustal imaging in the near future. Therefore, breakthroughs that reveal the three-dimensional tectonic structures in the Qinghai-Tibet Plateau will rely on the study of regional geophysical surveys. Along these lines, ground-observation gravity data with a resolution of $5 \mathrm{~km}$ was acquired by the China Geology Survey. As the regional gravity observations were carried out on uniform grids with accurate locations, where the regional gravity field is caused by density disturbances arising from different depths, three-dimensional crustal density structures and main deformation belts can be inferred from these data .

Over the years, with the support of the National Science Foundation of China and the China Geology Survey, we developed new methods for processing data and extracting information of potential fields. These methods include spectral analysis, multi-scale wavelet analysis, generalized inversions, and the scratch analysis methods, which can be combined into a systematic gravity data processing procedure (Fig. 1) for depicting three-dimensional crustal structures and deformation features. This new data processing set is called the multi-scale scratch analysis method. First, this data processing system uses the spectral analysis to determine if the regional gravity data can be decomposed into several sub-datasets and how many equivalent layers should be decomposed. Then, it uses the multi-scale wavelet analysis to decompose the regional gravity data into sub-anomalies according to different sources' depths which correspond to the desired equivalent layers. Next, the system inverses the density perturbation of each equivalent layer by using a generalized linear inversion. 
Finally, characteristics of the deformation belts in each equivalent layer are extracted using the scratch analysis method.

The multi-scale scratch analysis method is systematic and sophisticated, and in this work it has been applied to regional gravity data to extract information about deformation belts in the Qinghai-Tibet Plateau. Our analysis has reveals variations of the deformation belts and plane distribution features from the upper crust to the lower crust, and it provides new information for the study of the lithosphere that could not be obtained by surface geology. Our previous papers introduced the method of multi-scale scratch analysis and its applications (Yang et al., 2015a, b). In this paper, we focus on its application to the Qinghai-Tibet Plateau, show the revealed crustal density structures and deformation belts, and discuss the geological and tectonic implications of the resulting maps.

The main scientific issues discussed in this paper include: what are the differences between tectonic features in the upper, middle and lower crust? Do they present any new information that is significant to continental dynamics in the studied area? The multi-scale scratch analysis produces three sets of images (density disturbance, ridge coefficient, and edge coefficient images), which contain a wealth of information. Do these resulting maps have any relationships with their surface geology? These issues will be discussed in detail as follows.

\section{Brief introduction to the multi-scale scratch analysis}

In previous papers (Yang et al., 2015a, b), we use the regional gravity field in the Qinghai-Tibet Plateau as an example to introduce the method of the multi-scale scratch analysis, including spectral analysis for defining the equivalent density layers and estimating depth of the layers, decomposition of the gravity field using the multi-scale wavelet analysis, density inversion of decomposed gravity anomalies, and scratch analysis for locating deformation belts.

The multi-scale wavelet analysis of regional gravity field is based on the scale-depth law that a gravity anomaly generated by a single source body has the characteristic scale. The deeper the source locates, the larger the characteristic scale is. In addition, the characteristic scale of a surface Bourger gravity anomaly is approximately proportional to buried depth of 
the source (Hou and Yang, 1997; 2011). When comes to gravity anomalies superimposed by multiple source bodies, they no longer have the characteristic scale. The multi-scale wavelet analysis utilizes the characteristic scale to recover the characteristic scale in the ground superimposed anomalies, and decomposes them with different scales, making the decomposed wavelet details obtain characteristic scales again (Mallat, 1989; Hou and Yang, 1997). Thus the multi-scale wavelet analysis can delineate crustal density structures on equivalent layers at different depths.

Depth of each equivalent layer can be calculated using the depth equation of gravity wavelet details, which based on potential field theory in the wavenumber domain (Bhimasankakam et al., 1977; Yang et al., 1978). For a single source body, slope of the logarithmic power spectrum of its gravity anomaly is proportional to the source's buried depth. Accordingly, recognizable straight segments with different dipping slopes in spectral curves indicate buried depths of density disturbances corresponding to different equivalent layers. The steeper the straight segment in the power spectrum is, the deeper the equivalent layer is buried. In other words, if there appear a certain amount of recognizable straight segments with different slopes, the regional gravity field can be decomposed into sub-anomalous sets by applying the multi-scale wavelets analysis. In addition, the average depth of each sources' equivalent layer can be computed by using the depth equation to the decomposed wavelet details. After decomposing gravity anomalies with discrete wavelet transformation and computing the average depth of each equivalent layer, we should inverse the density disturbances using the generalized linear inversion method (Yang, 1987, 1997).

From physical point of view, crustal deformation belts can be regarded as scratches in the crust caused by past dynamic processes, causing strip-like rock densities anomalies in some narrow belts that are called ridge-like scratches. The typical feature of the crustal scratches in the density disturbances are linear shape with high anisotropic parameters. Furthermore, the long ridge-like density anomalous belts in the crust also cause linear scratches in regional gravity field, characterized by rapidly changing gravity gradients, strong anisotropy, and directionally stable anisotropy. These characteristic parameters are implicit in the second order spectral moment of the local gravity field. Based on the second spectral 
moments, we can calculate an integrated parameter, called the ridge coefficient, to locate the crustal deformation belts (Sun and Yang, 2014; Yang et al., 2015a). The ridge coefficient $\Lambda$ mainly expresses the density anisotropy: $\Lambda=0$ implies no ridge-like scratches around the local cells; while $\Lambda=1$ indicates the high anisotropy of the density that may in turn show existence of a deformation belt.

When we want to extract information of boundaries of a continental tectonic unit, the narrower the tectonic boundaries are, the more accurately the boundaries will be located. However, belts depicted by the ridge coefficients of $\Lambda>0.3$ are not often narrow. To delineate boundaries more sharply, a new parameter is be defined, which is called the edge coefficient MA (Sun and Yang, 2014; Yang et al., 2015a). Tests demonstrate that in crystallized regions, the ridge coefficient images reflect the Phanerozoic crustal deformation belts; but the ridge edge coefficient maps indicate boundaries of tectonic units.

\section{Analytical results}

The studied area ranges from latitude $20^{\circ}$ to $40^{\circ} \mathrm{N}$ and from longitude $75^{\circ}$ to $105^{\circ} \mathrm{E}$. The simplified tectonic map ( Ren and Xiao, 2004) and Remote sensing image of the area are shown in Fig. 2a and Fig. 2b, respectively. The Ministry of Land and Resources of the People's Republic of China completed ground gravity surveys in the Qinghai-Tibet Plateau. After data fusion of the ground Bouguer gravity data from the Qinghai-Tibet Plateau and the satellite gravity data in its surrounding areas, we can obtain the Bouguer gravity anomaly for the Qinghai-Tibet area. The data fusion is completed by first subtracting satellite free-air anomalies from the Bouguer gravity anomalies, then applying the trend analysis on the results to fill the blank areas and at last combining the result obtained after the trend analysis with that of Bouguer anomalies. The final result is regarded as the Bouguer gravity anomalies of the whole study area. The Bouguer gravity anomalies of the Qinghai-Tibet Plateau on a grid of $0.25^{\circ} \times 0.25^{\circ}$ as shown in Fig. 3 can be used for multi-scale decomposition via discrete wavelet transformation. Based on the power spectrum features, the gravity anomaly in the Qinghai-Tibet plateau has been decomposed into six layers where the corresponding wavelet details are combined into six sub-anomalous sets (D1+D2), (D3+D4), (D5+D6), D7, D8 and 
S8. After obtaining the six sub-anomalies, we computed the buried depths of the equivalent layers from the logarithmic power spectrum using the slopes of the spectral curves. The average buried depth of the equivalent layer $(\mathrm{D} 1+\mathrm{D} 2)$ is $3.03 \mathrm{~km}$, and the equivalent layer (D3+D4) has a depth of $12.83 \mathrm{~km}$. They are related to the top and middle of the upper crust, respectively. The equivalent layer (D5+D6) has buried depth of $19.52 \mathrm{~km}$, which reflects the crystalline basement of the upper crust. The density disturbance of this equivalent layer is inversed and shown in Fig. 4a. The equivalent layer D7 has an average buried depth of approximately $34 \mathrm{~km}$ and is located in the middle crust, and the inversed density disturbance image is shown in Fig. 5a. The equivalent layer D8 refers to approximately $52 \mathrm{~km}$, which corresponds to the lower crust in the Qinghai-Tibet Plateau; Fig. 6a shows the inversed density disturbance. The $8^{\text {th }}$-order wavelet approximation S8 may reflect the Moho surface relief; however we will make no discussion regarding this since this paper only studies density imaging within the crust.

The obtained density disturbances are too sparse to be studied the scratch analysis, so we interpolated them into $0.05^{\circ} \times 0.05^{\circ}$ using the krigging interpolation method. Next, the ridge coefficient, $\Lambda$, and edge coefficient, $\mathrm{M} \Lambda$, were generated using a sliding circular window with a radius of $0.5^{\circ}(10$ pixels $)$. The ridge coefficient, $\Lambda$, and edge coefficient, $\mathrm{M} \Lambda$, of the crystalline basement of the upper crust were calculated from the density disturbance of the equivalent layer (D5+D6), shown in Fig. 4b and 4c, respectively. Similarly, the middle crustal ridge coefficient and edge coefficient of the equivalent layer D7 are shown in Fig. 5b and 5c, respectively; the lower crustal ridge coefficient and edge coefficient of the equivalent layer D8 are shown in Fig. 6b and 6c, respectively. These three sets of density disturbance, ridge coefficient and edge coefficient images, correspond to the upper, middle and lower crust, respectively. Their geological and tectonic implications will be discussed as follows.

\subsection{The upper crustal scratches and tectonic structures}

Supposing an average density of the upper crustal equivalent layer of $2.81 \mathrm{~g} / \mathrm{cm}^{3}$ (Xiao et al., 2008; Yang et al., 2015a), then the density disturbance image of the gravity wavelet details (D5+D6) can be inversed. Figure 4a displays the inversed density disturbance from the 
regional gravity wavelet details (D5+D6) with a buried depth of $19.52 \mathrm{~km}$. Line-shape lower density belts or parallel low-density belts on the figure reflect deformation belts; while the lump-shape and normal density blocks indicate secondary tectonic units related to craton or orogenic terranes. Comparing with existing tectonic maps, one can recognize twelve terranes in Fig. 4a, which are (1) Tsaidam, (2) Longdong , (3) Qiantang, (4) Baryanhar-Songpan, (5) Kashmir, (6) Lhasa-Gangdise, (7) Changdu, (8) the Himalayas, (9) Chayuhe, (10)West Burma, (11) East Burma-Tengchong, and (12) Lanping-Simao. Detailed locations and distributions of these terranes are specified with numbers in Fig. 2a.

Fig. $4 \mathrm{~b}$ shows the ridge coefficient image of the upper crust at an average depth of 19.52 $\mathrm{km}$. On the simplified tectonic map in Fig. 2a, we labeled the deformation belts in alphabetical order. These belts are recognized by geologists, and coincide with the results of multi-scale scratch analysis in Fig. 4b. Because the Qinghai-Tibet plateau has exposed outcrops, the deformation belts are also clearly shown on the remote sensing image (Fig. 2b). These deformation belts include: (A) Alkin-Qilian belt, (B) East Kunlun-West Qinling, (C) Jinshajiang-Red River, (D) Shuanghu-Lancangjiang, (E) Bangong-Nujiang, (F) Karakorum, (G) Yarlung-Zangbo, (H) Main front thrust of the Indian plate, (I) Longmenshan, (J) Xianshuihe -Xiaojiang belt. Since the interiors of the terranes are more stable than marginal areas, most of the deformation belts are boundaries of the above-mentioned terranes. For example, the Jinshajiang-Red river deformation belt (C) is the eastern margin of the Changdu (7) and Lanping-Simao (12) terranes; the Bangong-Nujiang deformation belt (E) is the northern margin of the Lhasa-Gangdise (6) terrane; and the main front thrust of the Indian plate $(\mathrm{H})$ is the southern marginal edge of the Himalayas (8). These deformation belts can be clearly found on the crustal ridge coefficient map.

The edge coefficient image of the upper crust layer at $19.52 \mathrm{~km}$ is shown in Fig. 4c. Red lines of high edge coefficient value are dense and thin, providing location information for further divisions of secondary tectonic units.

\subsection{The middle crustal scratches and tectonic structures}

Supposing an average density of the middle crust equivalent layer of $2.91 \mathrm{~g} / \mathrm{cm}^{3}$ (Xiao et al., 2008; Yang et al., 2015a), then the density disturbance images of the wavelet detail D7 
can be inversed and shown in Fig. 5a. The equivalent layer D7, with average depth of $34 \mathrm{~km}$, corresponds to the middle crust of the Qinghai-Tibet Plateau. From Fig. 5a, maps of the ridge and edge coefficients are obtained by using the scratch analysis method, as shown in Fig. 5b and Fig. 5c, respectively.

Comparing Fig. 5a with Fig. 4a and Fig. 2a, one can see that scopes of high-density terranes, such as Qiangtang (3), Tsaidam (1), and Baryanhar (4), have decreased. In contrast, areas of the lower density terranes, such as the northern margin of the Qinghai-Tibet Plateau, Lhasa-Gangdise (6), and West Burma-Tengchong (10), have obviously increased in the middle crust. The low-density areas beneath the Changdu terrane (7) and Longmenshan belts (I) also expand into the middle crust. High-density areas to the south of the Qinghai-Tibet Plateau, including Kashmir (5), the Himalayas (8), and Chayuhe (9), have also expanded significantly.

Looking at the ridge coefficient image of the middle crust in Fig. 5b, the large area of dense and thin deformation belts in Fig. $4 \mathrm{~b}$ no longer exists. The middle crustal deformation belts are clearly indicated by a ridge coefficient of more than 0.5 , but they are significantly different to those of the surface and upper crust. Comparing Fig. 5b with Fig. $4 b$ and Fig. 2b, we can see that several deformation belts of the middle crust almost stand out as they were part of the upper curst albeit slightly offset. These deformation belts include the Alkin-Qilian belt (A), Karakorum (F), Yarlung-Zangbo (G), the main front thrust of the Indian plate $(\mathrm{H})$, Longmenshan (I), and Xianshuihe-Xiaojiang (J). The East Kunlun-West Qinling belt (B) has now been transformed into three discontinuous segments; the Jinshajiang-Red River belt (C) now also consist of three discontinuous segments, of which the two northern segments are renumbered as $\mathrm{C} 1$ and $\mathrm{C} 2$, while the southern one is completely disconnected with them and is instead connected with the Yarlung-Zangbo belt ( which we have relabeled as Y and called the Jinshajiang-Lancangjiang belt, according to its geographical location). The Shuanghu-Lancangjiang deformation belt (D) in the upper crust has disappeared from the middle crust. The Bangong-Nujiang deformation belt (E) is cut into two segments that are the northern Bangong deformation belt (E1) and the southern Nujiang deformation belt (E2).

Fig. 5c displays the edge coefficient image in the middle crust. High-edge coefficient 
lines in the map provide locations of the above-mentioned terranes. Compared with the surface simplified tectonic map in Fig. 1a, areas of the Qiangtang (3) and Tsaidam (1) terranes have decreased in the northern parts. In their northern margin, Kunlun-Alkin-Qilianshan (A, B) has connected to form a strip-like terrane with a strong negative density disturbance, as shown in Fig. 5a. Moreover, the Lhasa-Gangdise (6), Changdu (7), and East Burma-Baoshan terranes (11) are linked together, which is also shown in the strong negative density disturbance in Fig. 5a.

\subsection{The lower crustal scratches and tectonic structures}

Supposing that the average density of the lower crust equivalent layer is $2.97 \mathrm{~g} / \mathrm{cm}^{3}$ (Xiao et al., 2008; Yang et al., 2015a), the density disturbance images from the gravity wavelet detail D8 are shown in Fig. 6a. The wavelet detail D8, which has a buried depth of about 52 $\mathrm{km}$, is related to the lower crust of the Qinghai-Tibet Plateau.

Comparing Fig. 6a with Fig. 5a and Fig. 1a, only four recognizable high-density craton terranes are left in the lower crust: the Qiangtang (3), the Tsaidam (1), the Bayanhar (4), and the Lanping-simao terranes (12). The Longdong terrane (2) is no longer recognizable, and the East Burma-Baoshan terrane (11) is now connected with the Lanping-simao terrane (12), though areas of them are reduced in the lower crust. The scope of the three high-density terranes, the Kashmir (5), the Himalayas (8) and the Chayuhe (9), have increased significantly, and they are totally linked together in the lower crust. Accordingly, at the northern margin of the terranes, the low-density areas of the Lhasa-Gangdise (6) and the west Burma-Tengchong (11) terranes have further expanded so that the whole Lhasa-Gangdise (6) terrane has become a low-density area.

Figure. $6 \mathrm{~b}$ shows a ridge coefficient image of the lower crust. Deformation belts that have ridge coefficients more than 0.5 are dramatically different to belts in the middle crust. Comparing Fig. $6 \mathrm{~b}$ with Fig. $5 \mathrm{~b}$ and Fig. $2 \mathrm{a}$, one can see that the deformation belts of the lower crust still include the northern margin Alkin-Qilian belt (A), the north-west marginal deformation belt of Qiangtang and the Tsaidam tarrane (X), the northern Bangong deformation belt (E1), the southern Nujiang deformation belt (E2), the Karakorum (F), the Yarlung-Zangbo $(\mathrm{G})$, the main front thrust of Indian plate $(\mathrm{H})$, the Jinshajiang-Lancangjiang 
belt $(\mathrm{Y})$ and the central deformation belt of the west Burma-Tengchong terrane (Z). The east Kunlun-West Qingling deformation belt (B) and the northern two sections (C1 and C2) of the Jinshajiang-Red river deformation belt are blurred in the lower crust. The Xianshuihe-Xiaojiang deformation belt (J) has shortened and is displaced westwards.

An edge coefficient image of the lower crust is shown in Fig. 6c, where red lines in this figure have become clearer and continuous. The number of tectonic units in the lower crust has decreased. Areas of the Qiangtang (3), Tsaidam (1), and Baryanhar (4) terranes have obviously reduced. The negative density disturbances in northern margins of the plateau have lined up along the west Kunlun-Alkin-Qilianshan. The Lhasa-Gangdise (6), Changdu (7), and East Burma-Baoshan terranes are connected to each other and have become a single terrane. The Kashmir (5), Himalayas (8), Chayuhe (9), and west Burma-Tengchong terranes are also connected together.

\section{Discussion}

\subsection{Tectonic implications of resulting maps of the upper crust}

Among the recognized terranes in Fig. 4a, Tsaidam (1), Longdong (2), Qiantang (3), Baryanhar-Songpan (4), Kashmir (5), and Himalayas (8) are relatively high-density terranes. Crystalline basements of these terranes have a high density and therefore should be more rigid. Some of the high-density terranes could be cratonic massifs such as the Qingtang terrane (3), while some are orogenic zones, but may contain more craton fragments. For instance, although the Himalayas (8) terrane is an accretionary wedge of continental collisions, it may contain craton fragments due to the Indian Craton subducting beneath in. The density of the crystalline basement in the Kashmir (5) and Chayuhe (9) terranes is very high, so they form structural knots and differ from the Himalayas.

From Fig. 4b and Fig. 5c, one can also find obvious boundaries between the Himalayas (8) and Chayuhe (9) terranes. High densities in the Kashmir (5) and Chayuhe (9) terranes indicate they are rigid and difficulted to break in continental collisions, and they play a key role in forming the western and eastern structural knots. The Lhasa-Gangdise (6), Changdu (7), and West Burma-Tengchong terranes belong to lower-density terranes. As they have been 
Tethys island arc systems since the late Mesozoic, the Lhasa-Gangdise (6) and Burma-Tengchong terranes (11) show a large area of subduction accretionary wedges. Therefore, these terranes should contain a lot of water from the Tethys Ocean in rock pores and fissures, which results in lower crust density. As it is affected by diapiric intrusions from lower crustal channel flows, the Changdu (7) terrane is deformed and its density decreases from the upper crust to the lower crust; the effects of which will be discussed in the next two subsections.

in the ridge coefficient image of the upper crust in Fig. 4b, the most prominent feature in the map is that many dense and short scratches occur within the Qinghai-Tibet Plateau. As it is well known, the temperature and pressure in the upper crust are not very high, and the crystalline rocks usually suffer brittle deformations together with many short scratches. The subduction and collision of the Indian subcontinent to the Eurasian plate results in the Qinghai-Tibet plateau are shortened by over $1000 \mathrm{~km}$ in the North-South direction, while producing near West-East compressional deformations (Molnar, 1988; Meissner and Mooney, 1998; Jolivet and Hataf, 2001; Yang and Yu, 2014a, b). Under long-term strong compressive stresses, the brittle upper crust ruptured to form a large area of thin deformation belts in addition to crustal shortening and thickening. Thus, the dense and thin deformation blocks in Fig. $4 \mathrm{~b}$ are related to the Cenozoic crustal shortening process. There are also more than ten long curved scratches shown in Fig. 4b. For instance, deformation belts (A-J) marked in Fig. 1a are of this case. Here we see that the ridge coefficient images provide information about locations of the deformation belts, and about the shortening blocks caused by continental collisions.

Next, let us consider what kind of new information the edge coefficient image (Fig. 4c) can provide. Due to the subduction and collision of Indian subcontinent with the Eurasian plate, a lot of network-like fractures appear in the brittle upper crust. Therefore, cobweb-like fractures are distributed in the Qiangtang (3), Baryanhar-Songpan (4), Lhasa-Gangdise(6), Changdu (7), Hiamayas (8), and Chayuhe (9) terranes, which directly imply the consequences of the collision between the Indian and Eurasian continents. On the other hand, Fig. 4c contains more than a dozen long curved lines that have high edge coefficient, which are in 
accordance with strikes of terrane boundaries, and reflect the boundary locations of the upper crustal terranes.

\subsection{Tectonic implications of resulting maps of the middle crust}

As it is well known, the behavior and properties of the upper, middle, and lower crust are quite different. Rocks are primarily brittle and easily broken in the upper crust; whereas rocks in the lower crust have a lower viscosity coefficient and appear to be ductile so that the rocks may easily creep; finally, the middle crust contains strong water solutions that leads to horizontal detachment (Kirby and Kronenbegr, 1987; James, 1989; Meissner and Mooney, 1998; Jolivet and Hataf, 2001; Rogers, 2004). As a result, structural shapes of the upper, middle, and lower crust are markedly different, causing obvious distinctions in their density disturbance images.

In Fig. 5a, the increase of low-density areas in terranes such as Lhasa-Gangdise (6), Changdu (7) and northern merging of the Qiangtang (3) and Tsaidam (1) terranes from the upper crust to the lower crust reflects possible upward diapiric intrusions from lower crustal channel flows. The west Burma-Tengchong terrane, located by the eastern front thrust of the Indian plate, corresponds to a north-south low-density belt. In addition, the Tengchong area has a high heat flow and low electricity resistivity (Wang et al., 2002; Wang, et al., 2007). Therefore, we infer that this low-density belt reflects volcanic activity and the presence of a magma chamber beneath it. Accordingly, the expansion of the low-density areas may be related to the rising temperature and increasing fluid content. The expanding terranes to the south of the Qinghai-Tibet Plateau, such as Changdu (7), Kashmir (5) and Himalayas (8), are of the northern margin of the subducting India-Australian plate in the middle crust. Here, the subducting plate extends northward with increasing depth, producing enlarging areas of these high-density terranes.

From Fig. 5b, the Shuanghu-Lancangjiang deformation belt (D) has disappeared in the middle crust, and the Bangong-Nujiang deformation belt (E) is cut into two segments. Thus the Shuanghu deformation belt that cuts the Qiangtang terrane (3) belongs to a basement fault and that has no root in the middle and lower crust. The Bangong-Nujiang deformation belt (E) has roots in the middle and lower crust, and so it belongs to the suture zones. The multi-scale 
scratch analysis shows that a deformation belt can become discontinuous in the middle crust, which related to different dynamical processes in its different segments. Consequently, it not only provides information about deformation belts, but also their depth extension and stereoscopic processing patterns.

In the ridge coefficient map of the middle crust (Fig. 5b), two new deformation belts occur, which are not clearly present in the upper crust. They have been relabeled as (X) and (Z) in Fig. 5b. The deformation belt $\mathrm{X}$ is located to the south of the Alkin-Qilianshan deformation belt (A) and along the north-west margin of the Qiangtang terrane (3). This implies that the northern marginal zone of the Qinghai-Tibet Plateau underwent an independent deformation in the middle and lower crust because of the southward subduction of the Tarim-Alashan Cratons. The deformation belt $\mathrm{Z}$ is located to the west of the Nujiang deformation belt (E2), and at the center of the west Burma-Tengchong terrane. This deformation belt is termed as the central deformation belt of the west Burma-Tengchong terrane, whose location is in accordance with the front volcanic arc of the westward subduction zone, which is related to the subduction of the north-east margin of the Indian plate (Unsworth et al., 2005; Wang et al., 2007).

\subsection{Tectonic implications of the resulting maps of the lower crust}

Owing to the high temperatures and pressures in the lower crust, rocks with some rheological properties may have a lower viscosity coefficient, and hence easily creep. As a result, the tectonic attributes of structures in the lower crust are mainly dominated by their rheological properties. According to the thermodynamic principle that a body will expand when heated and shrink when cooled, rocks with strong rheology have decreasing densities with increasing temperatures, while rocks with high viscosity coefficients have higher densities. Craton terranes are relatively solid and have poor thermal conductivity, and therefore have lower temperatures, higher viscosity coefficients, and higher densities. On the contrary, orogenic accretionary terranes contain more cracks and fluids, and usually posses higher temperatures, lower viscosity coefficients and densities.

Comparing Fig. 6a with Fig. 5a, one can see that as temperature increase in the lower crust, the areas of the high-density terranes including Qiangtang (3), Tsaidam (1), Bayanhar (4), and 
Lanping-simao (12) terranes are reduced accordingly. The India-Australian plate that is subducting along the southern margin of the Qinghai-Tibet Plateau expands its area northward with an increase in depth. From the previous geophysical investigation profiles (Nelson et al., 1996; Yang, 2002; Unsworth et al., 2005; Wang et al., 2007), the subducting angle of the India-Australian plate increased rapidly at the lower crust of the Lhasa-Gangdise (6) terrane, probably causing rocks to break, melt and delaminate. Therefore, we infer that the density decrease of the Lhasa-Gangdise (6) terrane is caused by magmatic process and partial melting of the front edges of the India-Australian plate. As mentioned before, the North-South low density belt along the west Burma-Tengchong terrane is located along the eastward subduction zone of the Indian plate in the middle crust. However, the whole terrane becomes a low-density area in the lower crust, showing partially melt rocks that might cover the entire lower crust. Features of these kinds of density structures can be explained by the hypothesis of "channel flows" (Royden et al., 1997; Clark et al., 2000; Law et al., 2006; Grujic, 2006; Schoenbohm et al., 2006; Harris, 2007).

From the amplitudes of the density disturbance in Fig. 6a, the low-density zones in the lower crust can be divided into "source zones" and "squeezed flows". The source zones are regions of the strongest negative density perturbations, which are distributed in the Lhasa-Gangdise (6) terrane and the northwestern margin of the Qinghai-Tibet Plateau. In the lower crust, the Lhasa-Gangdise (6) terrane has a width of approximately $300 \mathrm{~km}$ and a density perturbation of -80 $\mathrm{mg} / \mathrm{cm}^{3}$, which should belong to the main source zone caused by the continental collision. The low-density belt of the northern margin of the Qinghai-Tibet Plateau in the lower crust spreads along the Alkin and Qilianshan, and has relatively broader width. Its density perturbation is between -80 and $+60 \mathrm{mg} / \mathrm{cm}^{3}$. Therefore, it also belongs to the source zones. The squeezed flows are lateral squeezed branches coming from the source areas, which have relatively weaker negative density perturbations and are located in the lower crust of the Changdu-Longmenshan, the Changdu-Lancangjiang, and the Karakorum-Tianshan belts. The low-density squeezed flows are restricted in some areas by probable lower crustal mass creeping. In the density disturbance image in Fig. 6a, there are two low-density mass branches that are squeezed from the lower crust at the eastern margin of the Qinghai-Tibet Plateau; one of which is from the Changdu to Yunnan Dali which extends southwards to the upstream of Salween in Burma. The other one comes from 
Changdu to Kangding, which extends northeast along Longmenshan. These channel flows are measured to be approximately $180 \mathrm{~km}$ in width.

The term "channel flow" originally referred to the movement of melting masses from, or within, the lower crust (Law et al., 2006; Clark et al., 2000; Unsworth et al., 2005; Grujic, 2006; Schoenbohm et al., 2006; Harris, 2007). We may expand its meaning to any rheological creeping motion along some channels, both in the vertical and horizontal directions. Thus the low-density disturbance belts in the lower crust must be intimately related to channel flows. The lower density anomalies of the crustal rocks may be mainly caused by lithological changes, an increase in fluid substances, and temperature and pressure changes. The increased temperature and fluid substances reduce rock densities, which can also stimulate creeping crustal motion. Therefore, the results of three dimensional crustal density imaging can provide indirect evidence for the study of channel flows in the lower crust.

From the latest research of the Qinghai-Tibet Plateau, flows in the lower crust can be divided into vertical channel flows and lateral channel flows. Granite bodies in the high Himalayan orogenic belt, formed during the post-collision epoch (40-20Ma), indicates vertical channel flows (Clark et al., 2000; Unsworth et al., 2005; Zeng, et al., 2011). These kinds of flows were generated by dehydrating sedimentary rocks in the middle-to-lower crust that re-melt upward. They are coincident with local small-scale, low-density anomalies in the middle and upper crust. The lateral channel flow is attributed to the partial melting of rocks due to penetrating low-density sea water from ancient oceans that subducted into the mantle. Such water reduces the melting temperature of solid rocks after the closure of the ancient oceans, causing partial melting and lateral channel flows. Both the low density source zones and squeezed flows in the lower crust may reveal these types of flows.

Next, the vertical channel flows can be generated by diapiric intrusions of the lower crust. Comparing the density structures in the middle (Fig. 5a) and lower crust (Fig. 6a), the low-density belts in the lower crust are broad and connected together. In the middle crust, however, they become narrower and discontinuous. In the upper crust, the belts turn into bead strings (see Fig. 4a). This arises from the fact that rapid reducing areas of the low-density belts in the middle and upper crust may reflect low-density diapiric intrusions from the lower crust to the upper crust. Due 
to the upward extrusion of the low-density material in the lower crust, the craton terranes might split accordingly and therefore numbers of high-density blocks increase in the upper crust. As seen from Fig. 5a, the middle crust in the Qinghai-Tibet area has four high-density terranes, which are the Qiangtang (3), Baryanhar (4), Tsaidam (1), and the Longdong (2) terranes; while in the lower crust, Longdong (2) is no longer a high-density terrane and the area of Bayanhar (4) becomes very small. Therefore, the upwards extruding positions of the low-density mass located along boundaries of these blocks represent the diapiric intrusions of the lower crustal source zones or squeezed flows.

Deformation belts recognized from ridge coefficient image in the lower crust (Fig. 6b) are dramatically different to belts in the middle crust (Fig. 5b). From the view of deformation attributes, both the Alkin-Qilian belt (A) and the main front thrust of the Indian plate (H) belong to front deformation belts of the continental subduction aone; Yarlung-Zangbo $(G)$ is the deformation belt of the plate collision; and the North-west marginal deformation belt of the Qiangtang and Tsaidam terranes $(\mathrm{X})$ and the northern Bangonghu deformation belt (E1) are craton peripheral deformation belts, mostly associated with ancient terrane collisions. The southern Nujiang deformation belt (E2), Karakorum (F), Jinshajiang-Lancangjiang belt (Y) and the Xianshuihe-Xiaojiang deformation belt (J) are deformations associated with strike-slip motions. The central deformation belt of the West Burma-Tengchong terrane $(Z)$ meets the volcanic belt of the plate subduction front. Therefore, the lower crustal scratches can indicate five types of tectonic structures, including (1) Phanerozoic collisional suture zones, (2) front deformation belts of the continent-continent subduction, (3) suture zone of ancient terranes, (4) strike-slip deformation belts, and (5) volcanic belts in plate subduction zones.

Finally, let us consider the edge coefficient image of the lower crust shown in Fig. 6c. The growing rheological motion in the lower crust leads to material fusion and homogenizing, thus the number of tectonic units in the lower crust decreases. Though areas of the Qiangtang (3), Tsaidam (1), and Baryanhar (4) terranes are obviously reduced, their roots are still preserved in the lower crust, showing they are craton terranes. The separate strip-like terrane with negative density disturbances, called the west Kunlun-Alkin-Qilianshan terrane in the lower crust, is one of the source zones of the lower crustal channel flows in the Qinghai-Tibet plateau. The terrane 
connected by the Lhasa-Gangdise (6), Changdu, and East Burma-Baoshan terranes, has a strong negative density (Fig. 6a), which contains the source zone and squeezed flows in the lower crust. The terrane connected by Kashmir (5), the Himalayas (8) and Chayuhe (9), and the west Burma-Tengchong terranes has a high density, reflecting the northern edge of the Indian plate in the lower crust. Utilizing the edge image shown in Fig. 6c and comparing with the density disturbance in Fig. 6a, one may well delineate lower crustal structures of the plateau.

\section{Conclusions}

Applying the multi-scale scratch analysis to Qinghai-Tibet Plateau produces three sets of density disturbance, ridge coefficient and edge coefficient images. The density disturbance images can be used to delineate the hardness and rheological properties of continental tectonic units. The ridge coefficient images can be used to delineate deformation belts, and the edge coefficient images can be used to determine the positioning the boundaries of the structural division of the units. These images provide crustal geological and tectonic information from different aspects with depth information, able to give quantitative constrains to any possible tectonic models. To the upper crust, these results are basically coincident with surface geological and tectonic mapping. They can also provide more structural information of the middle and lower crust, which conventionally is hard to be accurately inferred. For instance, the density disturbance images show the source-zones and squeezed flows of channel flows in the lower crust, as well as the position of subduction front of the Indian plate beneath the Himalayan mountain range. The ridge coefficient images provide the positions of suture zones, deformation and subduction volcanic belts, ancient terrane collision belts and strike-slip zones. By Combining these with the edge coefficient images one can draw out tectonic maps with different structural units in the middle and lower crust. For example, very high density terranes such as the Kashmir (5) and Chayuhe (9), are divided from the Himalayas (8) terrane, giving physical reasons for formation of the western and eastern structural knots in the India-Eurasia collisional belt. The multi-scale scratch analysis not only provides plane geometry of the structures and deformation belts, but also their depth extension and stereoscopic patterns. For instance, a decrease of the low-density volume from the lower crust to the upper implies possible diapiric intrusions of the low-density channel flows. However, this newly developed method needs more tests worldwide and further improvement of its computational 
procedures.

\section{Acknowledgement}

This work is supported by National Science Foundation of China with the project number \#41574111 and Chinese Geological Survey with the project number\#12120113093800. 


\section{References}

Avouac, J.P., Tapponnier, P., 1993. Kinematic model of active deformation in central Asia. Geophys. Res. Lett. 20: 895-898.

Bhimasankakam, V.L.S., Nagendra, Seshagiri, R., 1977. Interpretation of gravity anomalies due to finite inclined dikes using Fourier transformation. Geophysics. 42(1): 51-59.

Clark, M.K., Royden, L.H., 2000. Topographic ooze: Building the eastern margin of Tibet by lower crustal flow. Geology. 28(8): 703-706.

Grujic, D., 2006. Channel flow and continental collision tectonics: an overview. Geol Soc London. 268:25-37.

Harris, N., 2007. Channel flow and the Himalayan-Tibetan orogen: a critical review. Geol Soc London. 164: 511—523.

Harrison ,T.M., Copeand, P., kidd, W.S.F., Yin, A., 1992. Raising Tibet. Science. 255: 1663-1670.

Hou, Z.Z., Yang, W.C., 1997. Wavelet transform and multi scale analysis of gravity field in China (in Chinese). Chinese J. Geophysics. 40(1): 85-95.

Hou, Z.Z., Yang, W.C., 2011. Multi-scale inversion of density structure from gravity anomalies in Tarim Basin. Sci. in China. Ser. D. 54(3): 399-409.

Jolivet, L., Hataf H-C. 2001. Geodynamics. Lisse: A.A.Balkema Pub.

James, D.E., (Ed.), 1989. Encyclopedia of solid Earth geophysics. New York: Van Nostrand Reinhold Com.

Kirby, S.H., Kronenbegr, A.K., 1987. Rheology of the Lithosphere: selected topics. Geophys. Rev. 25: 1219-1224.

Law, R.D., Searle, P., Godin, L., eds., 2006. Channel flow, ductile extrusion and exhumation in continental collision zones. Geological Society. London. special pub. 268 .

Mallat, S., 1989. Multifrequency channel decomposition and wavelet models. IEEE Transactions on Acoustics, speech, and signal processing. 37(12): 2091-2110.

Meissner, R., Mooney, W., 1998. Weakness of the lower continental crust: a condition for delamination, uplift, and escape. Tectonophysics. 296: 47-60.

Molnar, P., Paul, T., 1975. Cenozoic Tectonics of Asia: effects of a continental collision. Science. New Series. 189( 4201): 419-426.

Molnar, P., 1988. A review of geophysical constrain of the Himalaya on the deep 
structure of the Tibetan Plateau, the Himalaya and the Karakoram, and their tectonic implications. Royal of London Philosophical Transactions. ser. A, v. 326, p. $33-88$

Nelson, K.D., Zhao, W.J., Brown, L.D., et al., 1996. Partially molten middle crust beneath southern Tibet: synthesis of project INDEPTH results. Sciences. 274(5293): 1684-1688.

Ren J.S., Xiao, L.W., 2004, Lifting the mysterious veil of the tectonics of the Qinghai-Tibet Plateau by 1:250000 geological mapping (in Chinese). Geological Bulletin of China, 23(1): 1-11.

Rogers, J.W., 2004. Continents and Supercontinents. Oxford : Oxford Univ. Press.

Royden, L.H., Clark, B., King, R.W., et al. 1997. Surface deformation and lower crustal flow in eastern Tibet. Science. 276(5313): 788-790

Schoenbohm, L.M., Burchfiel, B.C., Chen, L., 2006. Propagation of surface uplift, lower crustal flow, and cenozoic tectonics of the southeast margin of the Tibetan Plateau. Geology. 34(10): 813-816

Sun, Y.Y., Yang, W.C., 2014. Recognizing and extracting the information of crustal deformation belts from the gravity field (in Chiese). Chinese J. Geophys. 57(5): 1578-1587.

Unsworth, M., Jones, A.J., Wei, W., et al., 2005. Crustal rheology of the Himalaya and Southern Tibet inferred from magnetotelluric data. Nature. 438|3,doi:10:78-81.

Wang, C.Y., Han, W.B., Wu, J.P., et al., 2007. Crustal structure beneath the eastern margin of the Tibetan Plateau and its tectonic implications. Journal of geophysical research, 112(B7): B07307, doi:10.1029/2005JB003873.

Wang, C.Y., Luo, H., Wu, J.P., Bai, Z.M., Huang, F.,G., 2002. Seismological study on the crustal structure of Tengchong Volcanic geothermal area. Acta seismologica sinica. 15(2): 247-259.

Wang, Y., Zhang, X.M., Jiang, C.S., Wan, J.L., 2007, Tectonic controls on the late Miocene-Holocene volcanic field along the southern margin of the Tibetan plateau. Journal of Asian Earth Science. 30(2): 375-389.

Yang, W.C., Guo, A.Y., Zhao, J.X., et al., 1978. Theory and methods for interpretation of gravity and magnetic anomalies in the frequency domain (in Chinese). Bull InstGeophysGeochem Prospect. 78(2): 134-178. 
Yang, W.C., 1987. Generalized inversion applying in potential field data calculation(in Chinese). Acta Geophys Sin. 30(3): 283-291.

Yang, W.C., 1997. Theory and Methods in Geophysical Inversion (in Chinese). Beijing: Geological Publishing House.

Yang, W.C., 2002. Geophysical profiling across the Sulu ultra-high-pressure metamorphic belt, Eastern China. Tectonophysics. 354: 277-288.

Yang, W.C., Yu, C.Q., 2014a. Continental collision process reveled by worldwide comparison of crust and upper mantle structures (I) (in Chinese). Geoloical review. 60(2): 237-259.

Yang, W.C, Yu, C.Q., 2014b. Continental collision process reveled by worldwide comparison of crust and upper mantle structures (II) (in Chinese).Geoloical review. 60(3):486-502.

Yang, W.C, Yu, C.Q., Sun, Y.Y., Hou, Z.Z., 2015a. The Multi-Scale Scratch Analysis Method for Quantitative Interpretation of Regional Gravity Field. Chinese J. Geophysics. 58(1): 41-53.

Yang W.C, Yu, C.Q., Hou, Z.Z., 2015b. The three dimensional density structures of Qinghai-Tibet Plateau and crustal mass movement. Chinese J. Geophysics(in Chinese). 58(11): 4223-4234.

Yuan, X.C., Jiang, M., et al., 2008. The three-dimensional structure of lithosphere and its evolution in the northeast part of China (in Chinese). Beijing: Geological Publishing House.

Xu, Z., Yang, W., Ji, S., et al., 2009. Deep root of a continent-continent collision belt: evidences from the CCSD deep borehole in the Sulu ultrahigh pressure metamorphic terrane. China. Tectonophysics. 475 issue 2: 204-219.

Zeng L, Li-E Gao, Kejia Xie, Jing Liu-Zeng, 2011, Mid-Eocene high Sr/Y granites in the Northern Himalayan Gneiss Domes: Melting thickened lower continental crust. Earth and Planetary Science Letters, 303, 251-266. 
Reginal Gravity Data

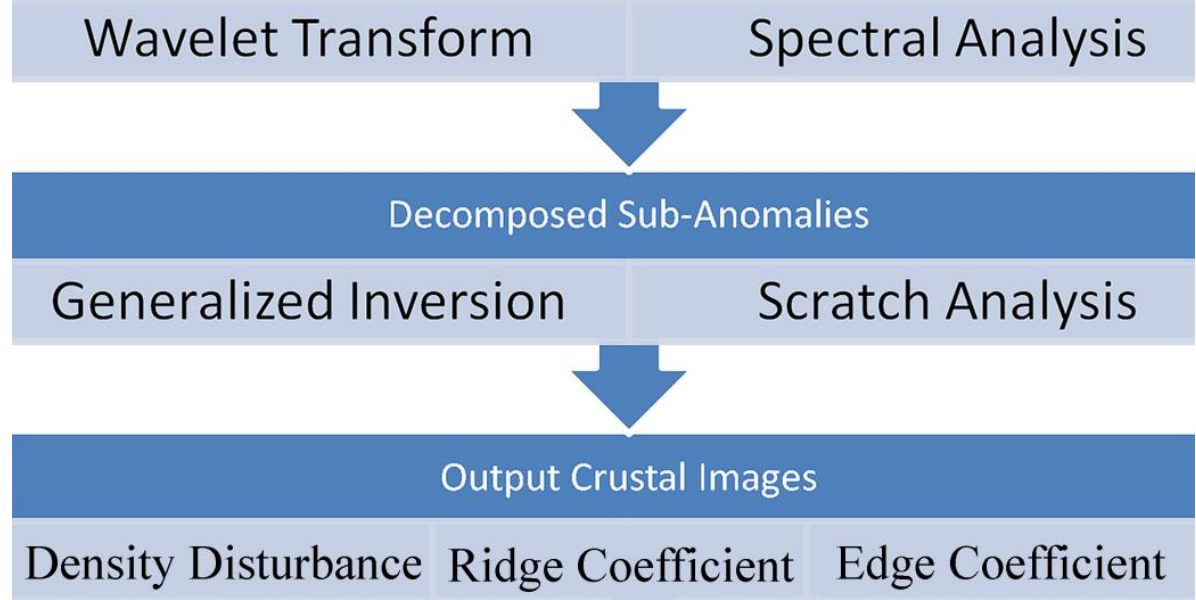

Figure 1. Flow-chart of the multi-scale scratch analysis of regional gravity data processing of the Qinghai-Tibet Plateau. 
(a)

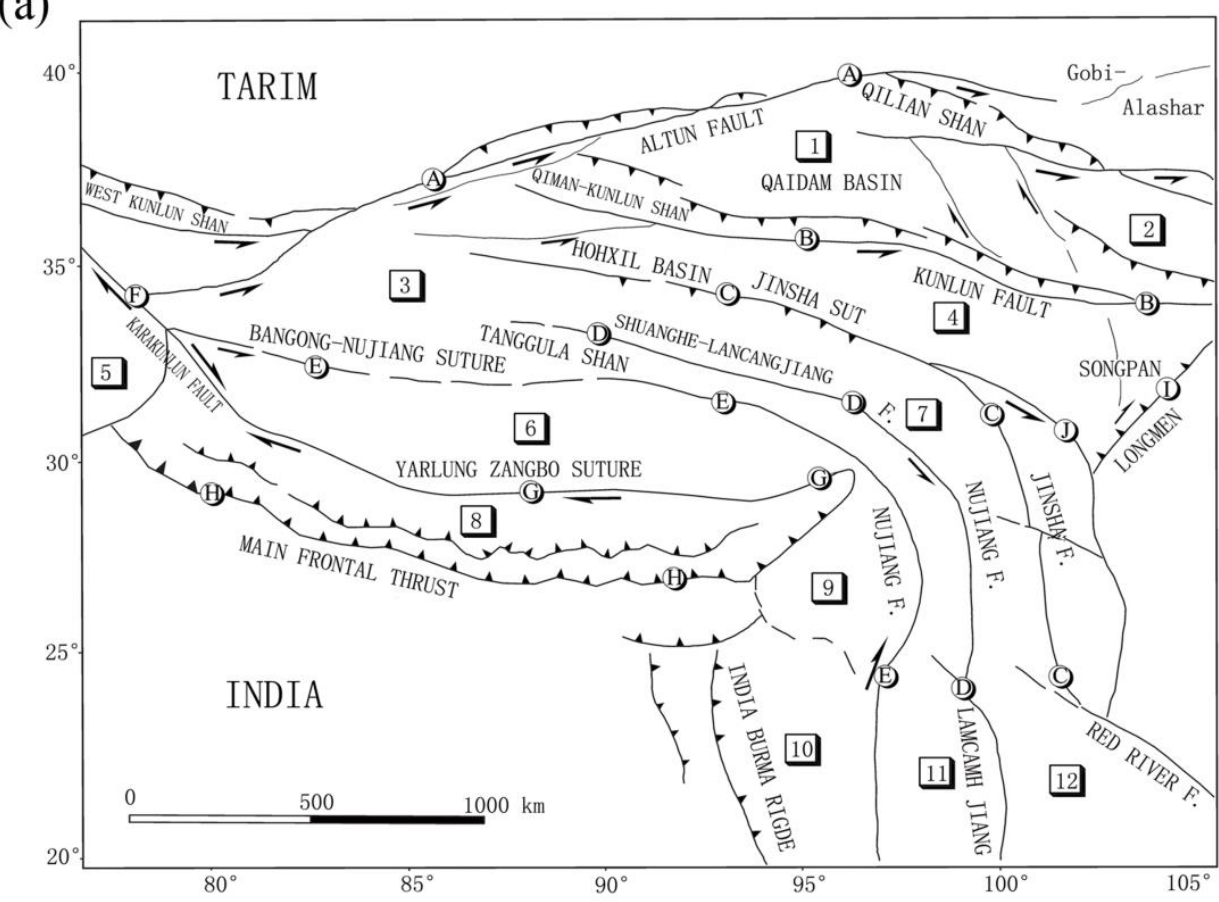

(b)

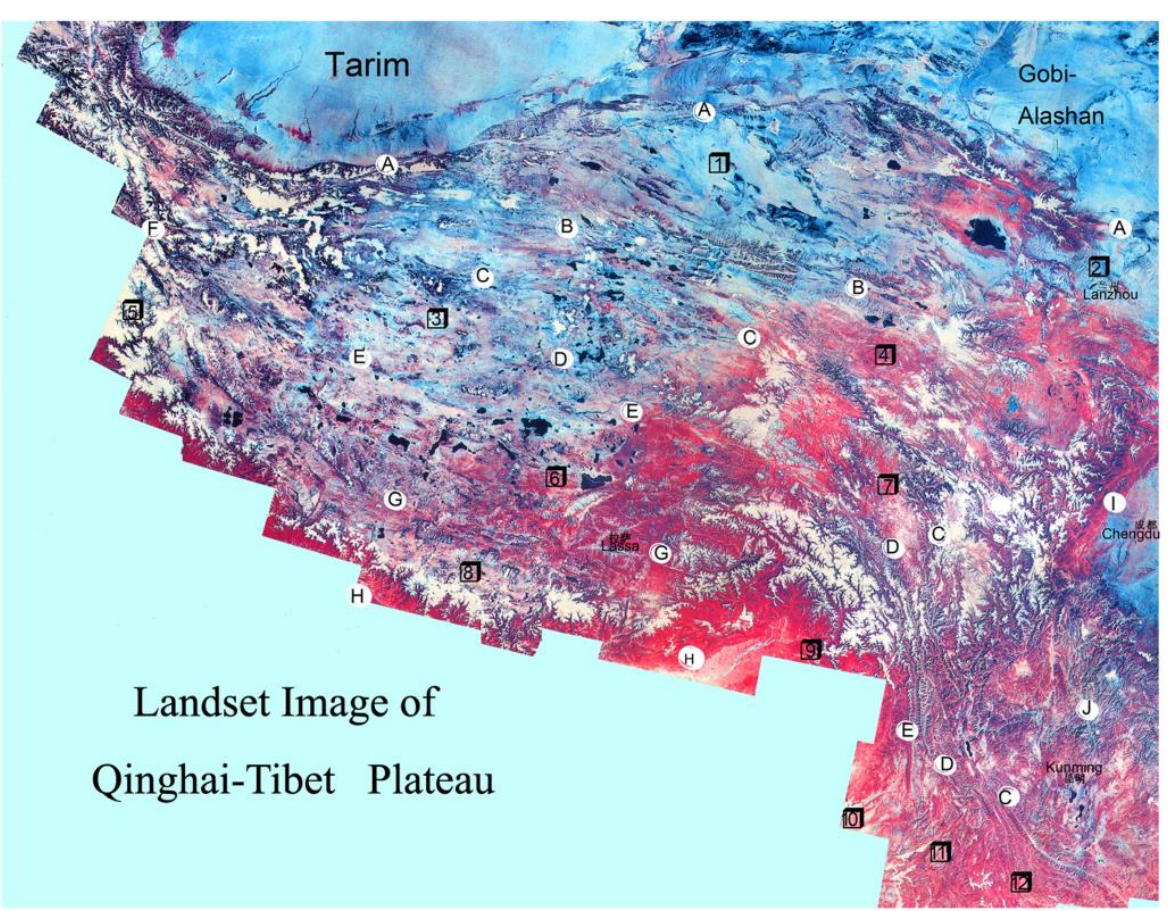

Figure 2. (a) Simplified tectonic map of the Qinghai-Tibet Plateau; (b) Remote sensing image of the Qinghai-Tibet obtained by the LANDSET satellite.

Terranes: 1: Tsaidam, 2: Longdong, 3: Qiangtang, 4: Baryanhar-Songpan, 5: Kashmir, 6:

Lhasa-Gangdise, 7: Changdu, 8: Himalayas, 9: Chayuhe, 10: West Burma, 11: East

Burma-Tengchong, 12: Lanping-Simao.

Deformation belts: A: Northern margin Alkin-Qilian belt, B: East Kunlun-West Qinling, C: 
Jinshajiang-Red River, D: Shuanghu-Lancangjiang, E: Bangong-Nujiang, F: Karakorum, G: Yarlung-Zangbo, H: Main front thrust of India plate, I: Longmenshan, J: Xianshuihe -Xiaojiang belt. 


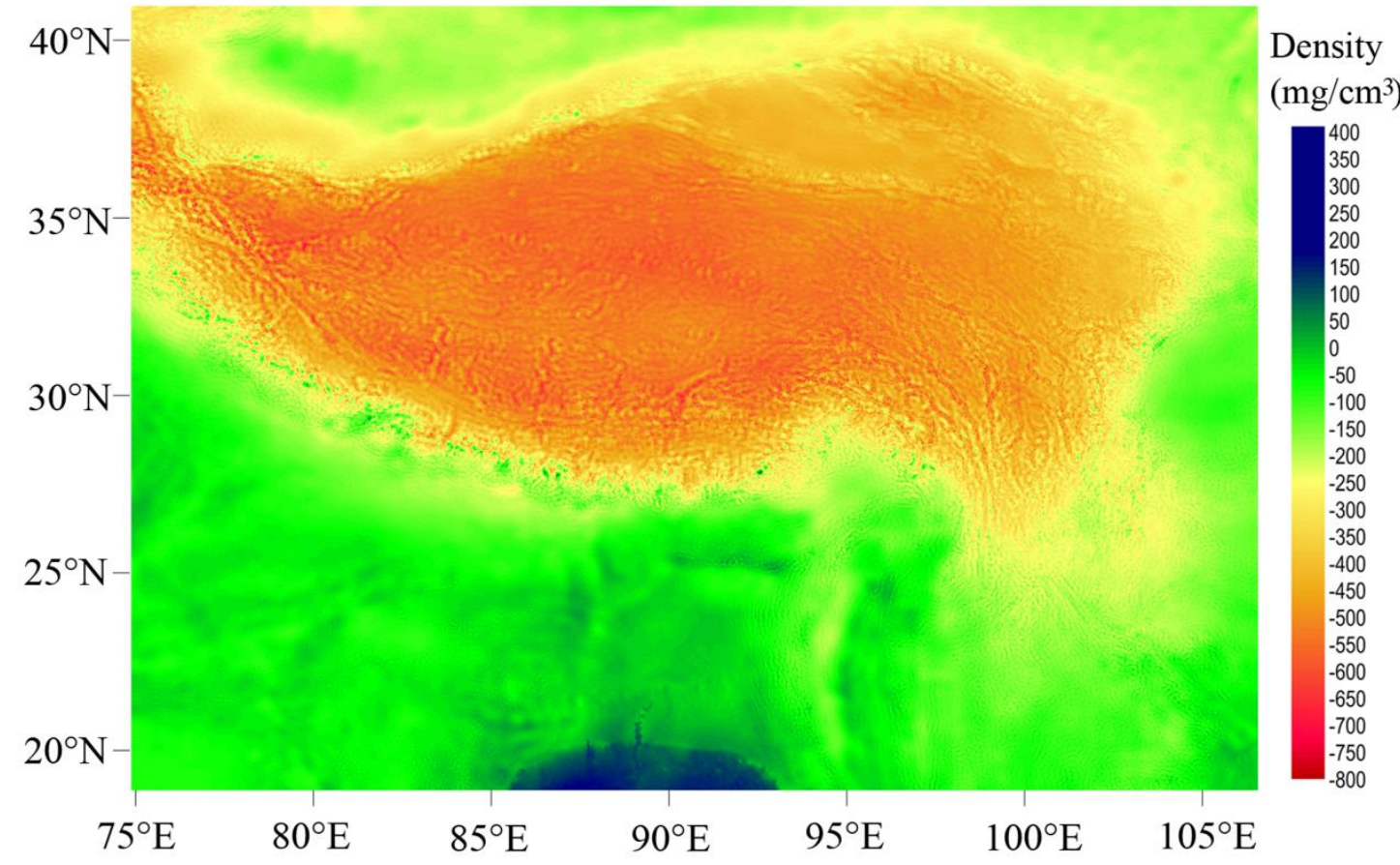

Figure 3. Bouguer gravity anomaly of the Qinghai-Tibet Plateau. 

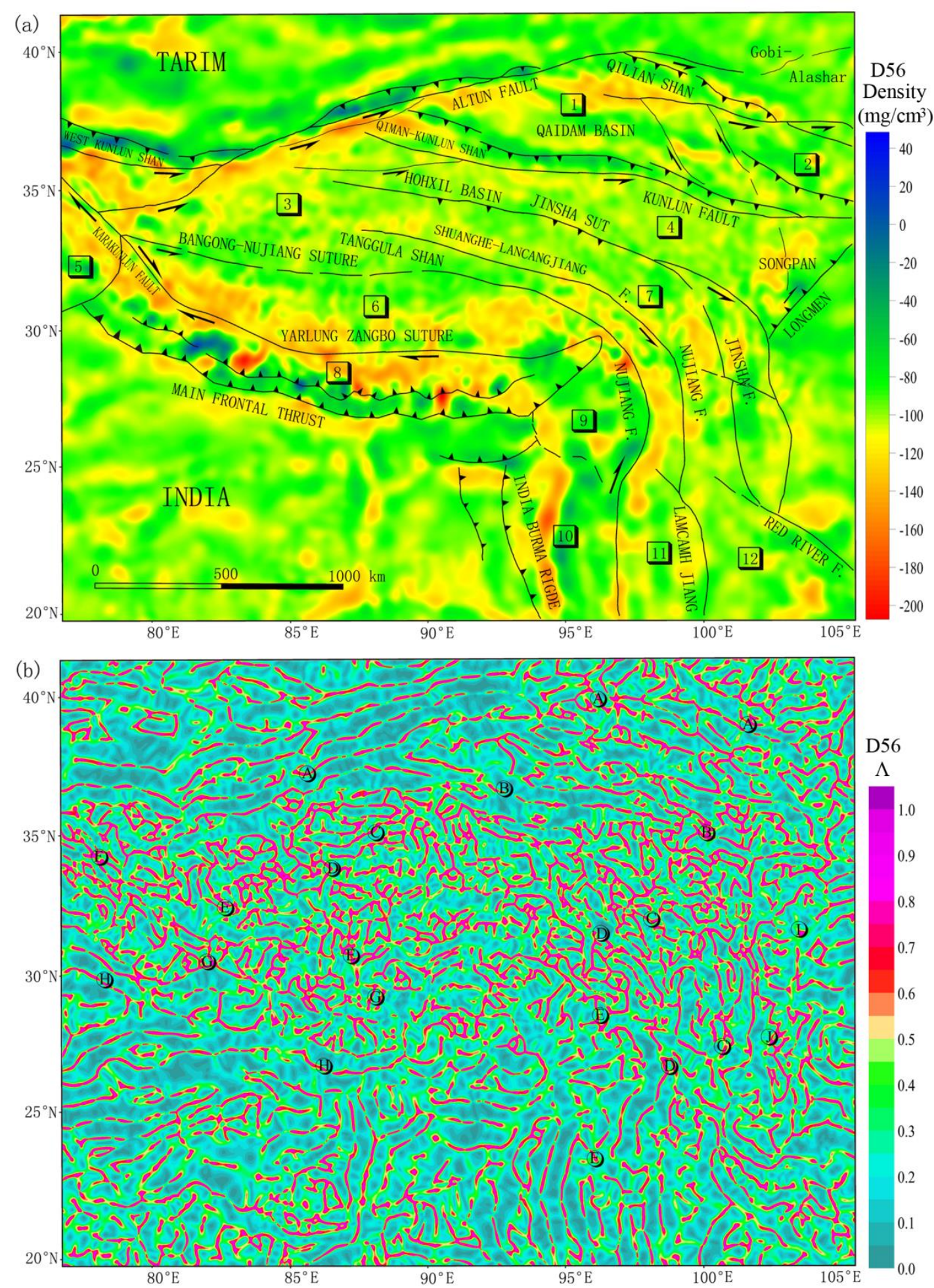


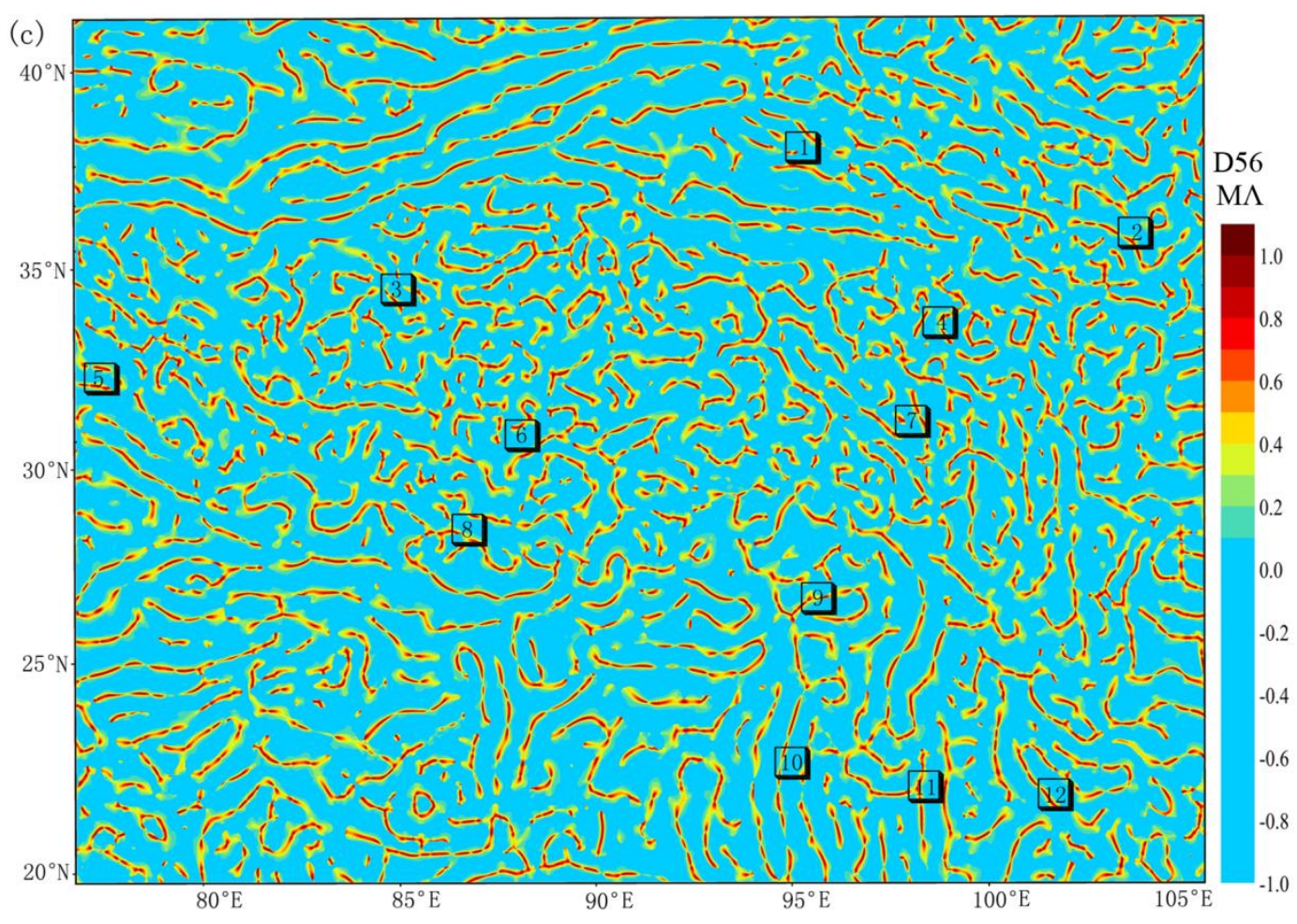

Figure 4. Density disturbance image (a), ridge coefficient image (b) and the corresponding edge coefficient image (c) of the upper crust plane, which has an average depth of $19.52 \mathrm{~km}$, referring to wavelet details $(D 5+D 6)$. The color-scale unit in Fig. 4 a is $\mathrm{mg} / \mathrm{cm}^{3}$. 

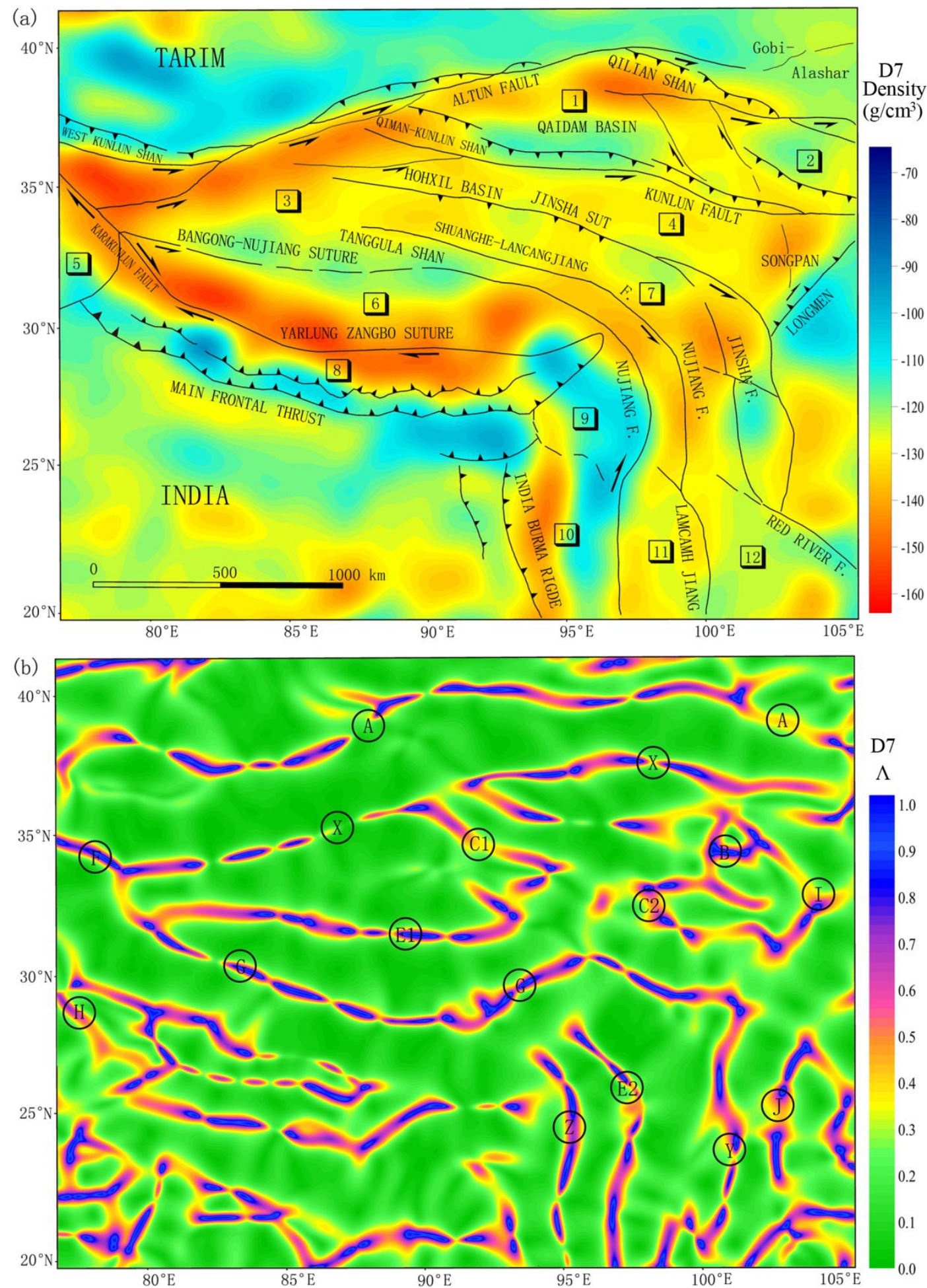


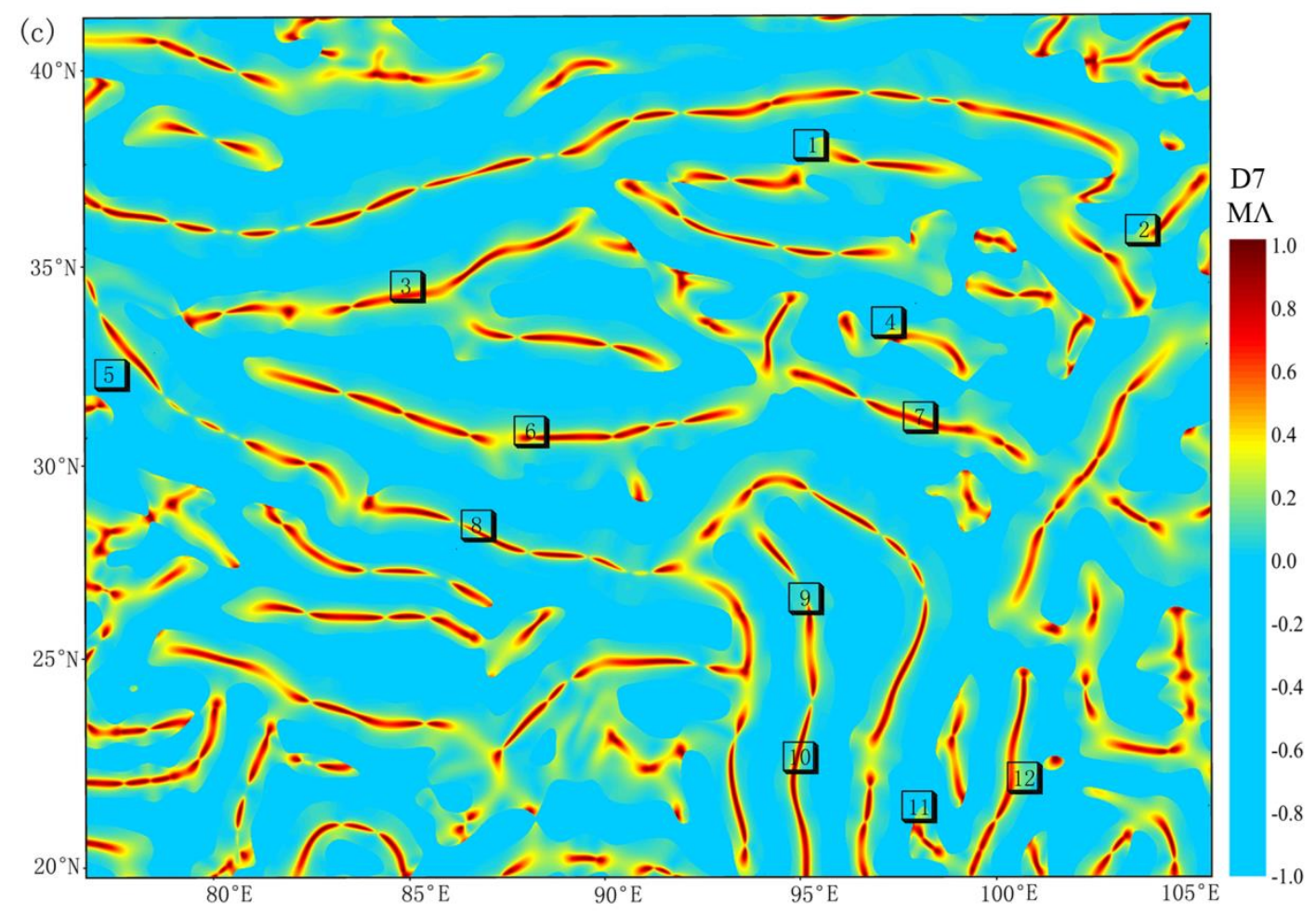

Figure 5. Density disturbance image (a), ridge coefficient image (b) and the corresponding edge coefficient image (c) of the middle crust plane, which has an average depth of $34 \mathrm{~km}$, referring to wavelet detail D7. The color-scale unit in Fig. $5 \mathrm{a}$ is $\mathrm{mg} / \mathrm{cm}^{3}$. Deformation belts $\mathrm{X}$ and $\mathrm{Y}$ in figure $5 \mathrm{~b}$ are newly found deformation belts 

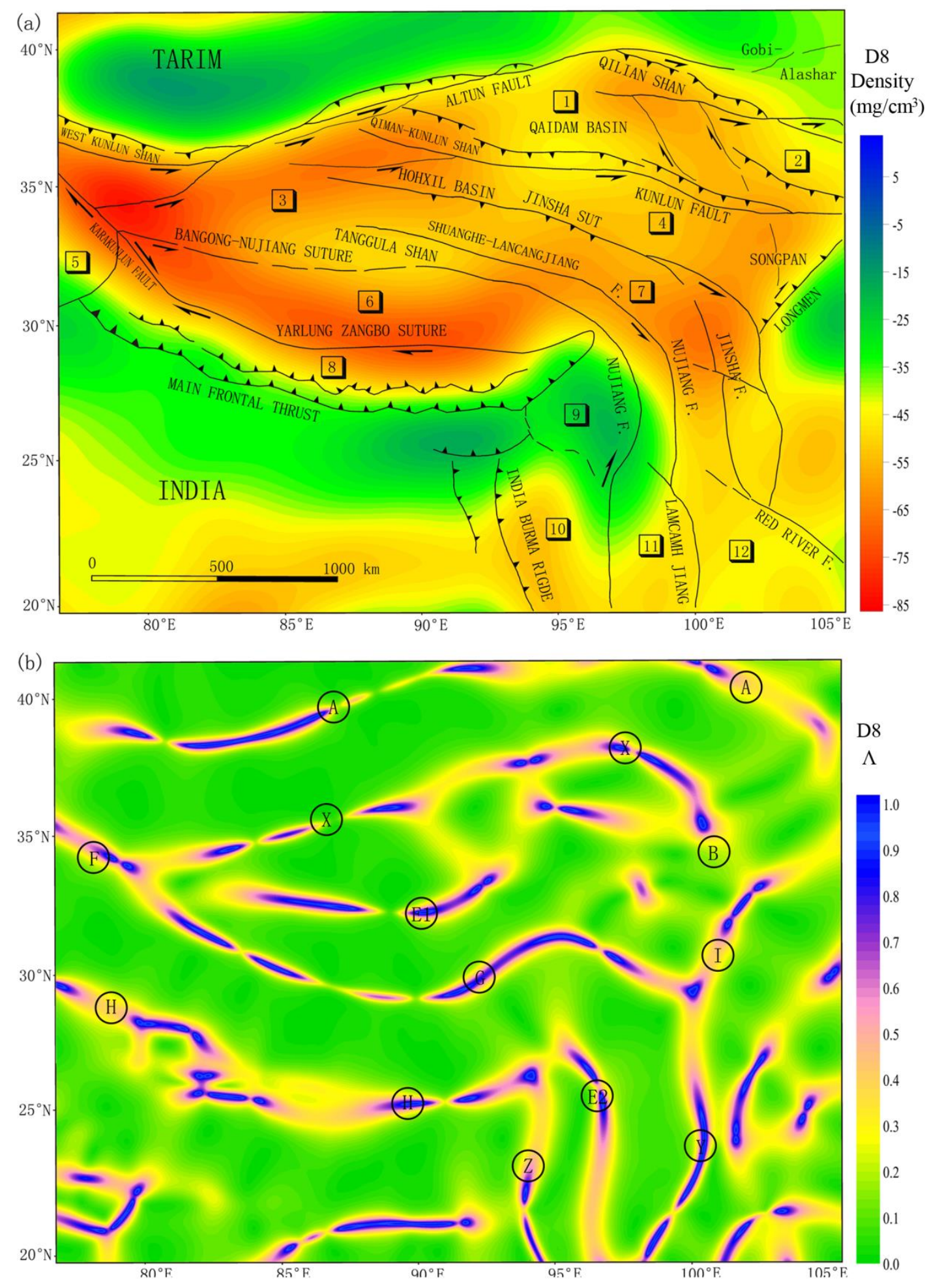


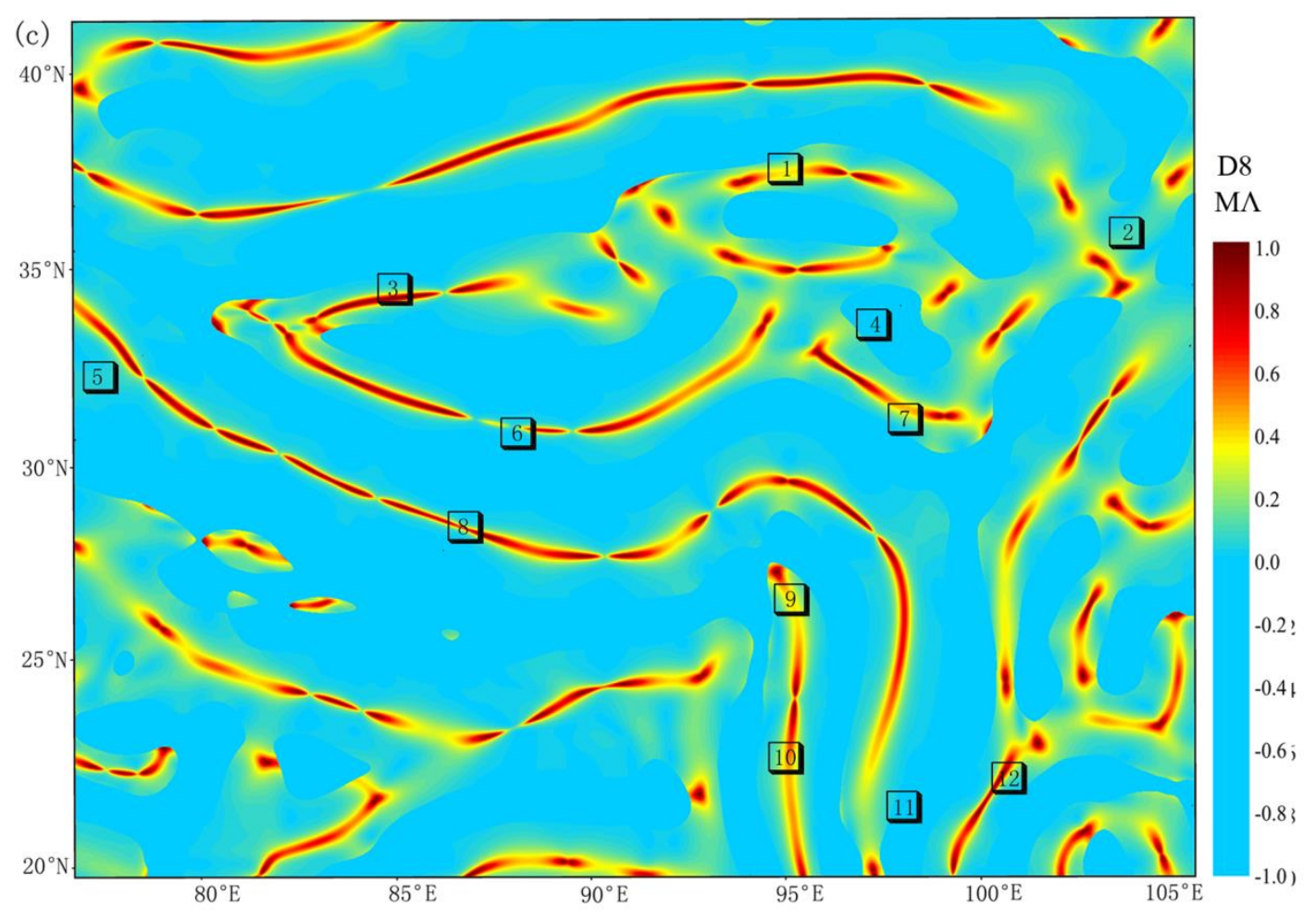

Figure 6. Density disturbance image (a), ridge coefficient image (b) and the corresponding edge coefficient image (c) of the lower crust plane, which has an average depth of $52 \mathrm{~km}$, referring to wavelet detail D8. The color-scale unit in Fig. $6 \mathrm{a}$ is $\mathrm{mg} / \mathrm{cm}^{3}$. 